\title{
Perancangan Sistem Informasi Helpdesk Menggunakan Website Design Methode Dalam Mendukung Tata Kelola Teknologi Informasi
}

\author{
R Wisnu Prio Pamnungkas, Allan D Alexander, Ali Reza \\ Universitas Bhayangkara \\ Jl Raya Perjuangan Marga Mulya, Bekasi Utara, (021) 88955882 \\ wisnu.prio@dsn.ubharajaya.ac.id11), allan@ubharajaya.ac.id²), \\ reza.ali.mountazery236@gmail.com ${ }^{3)}$
}

\begin{abstract}
Information Technology is important in increasing efficiency and efficiency in achieving company goals. Is a regionally owned company that in carrying out the functions and duties of clean water services for customer needs is never separated from the company's services to customers. Thus the helpdesk application is designed as a Single Point of Contact to focus on customer service issues. The purpose of this research is to analyze and manage the helpdesk application with a display design using the website design method. Built with PHP and MySql database, the application aims at implementing ITIL, which is useful for managing and assisting any problems (reporting) and service requests (requirements) to be sent to the unit that manages the handling schedule based on priority weights.
\end{abstract}

Keywords: Helpdesk, website, ITIL, service, priority weight

\begin{abstract}
Abstrak
Teknologi Informasi merupakan hal penting dalam meningkatkan efisiensi dan efisiensi untuk mencapai tujuan perusahaan. Adalah sebuah perusahaan milik daerah yang dalam menjalankan fungsi dan tugas pelayanan air bersih untuk keperluan pelanggan tidak pernah lepas dari layanan perusahaan pada pelanggan. Dengan demikian aplikasi helpdesk dirancang sebagai Satu Titik Kontak (Single Point of Contact) untuk dipusatkan pada masalah layanan pelanggan. Tujuan dari penelitian ini adalah untuk menganalisis dan mengelola aplikasi helpdesk dengan rancangan tampilan menggunakan metode rancangan website (Website Design Method). Dibangun dengan PHP dan basis data MySql, aplikasi bertujuan implementasi ITIL yang berguna untuk mengelola dan membantu setiap masalah (pelaporan) dan permintaan layanan (requirement) agar dikirim ke unit yang mengatur jadwal penanganan berdasarkan bobot prioritas masalah.
\end{abstract}

Kata Kunci: Helpdesk, website, ITIL, layanan, bobot prioritas

\section{PENDAHULUAN}

Adalah sebuah perusahaan daerah di kota Bekasi, yang bergerak dalam distribusi air bersih bagi masyarakat kota Bekasi. Salah satu misi perusahaan adalah memberikan layanan air minum bagi masyarakat Kota Bekasi yang terjamin kualitas, kapasitas dan kuantitasnya[1-12]. Keberadaan instansi ini juga dirasakan cukup membantu masyarakat dalam memenuhi kebutuhan air bersih di daerah Kota Bekasi. Hal tersebut juga berpengaruh terhadap peningkatan konsumen di tahun 2015 jumlah konsumen sebanyak 26.864. Sementara di tahun 2016 tercatat 28.044 konsumen, lanjut ke tahun 2017 naik 29.343 konsumen [13]. 
Perusahaan telah beroperasi dalam menjalankan fungsi dan tugas untuk mengelola air bersih bagi kepentingan masyarakat atau pelanggan tidak pernah terlepas dihadapkan pada pengaduan atau keluhan pelanggan terhadap masalah seperti water meter yang rusak, pipa saluran air yang bocor dan penyaluran air yang berhenti. Berdasarkan observasi yang dilakukan mengenai kondisi saat ini perusahaan terdapat dua bagian yang menjalani tugas untuk menerima pengaduan dari pelanggan yaitu bagian Hubungan Masyarakat (Humas) dan Hubungan Langganan (Hublang). Humas pada perusahaan merupakan bagian yang termasuk dalam Seksi Urusan Hukum dan berkedudukan langsung di bawah Kepala Bagian Umum, sedangkan Hublang berkedudukan sejajar dengan Bagian Umum yang mempunyai tugas menyelenggarakan tugas-tugas pengelolaan data langganan dan menyelenggarakan pemasaran layanan. Bagian Humas dan Hublang keduanya merupakan jalur utama bagi perusahaan karena menjadi pusat segala informasi yang berasal dari pelanggan ke perusahaan maupun sebaliknya.

Tabel 1. Laporan Pengaduan Pelanggan 2017

\begin{tabular}{|c|c|c|c|c|}
\hline \multirow{2}{*}{ No. } & \multirow{2}{*}{ Masalah } & \multicolumn{2}{|c|}{ Sampai Bulan Ini } \\
\cline { 3 - 5 } & Air Kecil & Jumlah & Selesai & Belum \\
\hline 1. & Air Keruh & 147 & 109 & -38 \\
\hline 2. & Air Tidak Keluar & 165 & 160 & -5 \\
\hline 3. & Angka Meter Mundur & 117 & 99 & -18 \\
\hline 4. & Lock Able & 0 & 0 & 0 \\
\hline 5. & Meter Buram & 177 & 54 & -1 \\
\hline 6. & Meter Hilang & 3 & 2 & -123 \\
\hline 7. & Meter Mati & 137 & 94 & -43 \\
\hline 8. & Meter Rusak & 1.236 & 638 & -598 \\
\hline 9. & Meter Tidak Disegel & 0 & 0 & -43 \\
\hline 10. & Meter Tidak Normal & 98 & 55 & -1 \\
\hline 11. & Meter Tidak Terbaca & 1 & 0 & -10 \\
\hline 12. & Pasang Meter Kembali & 12 & 2 & -2 \\
\hline 13. & Pemas SL Baru & 10 & 8 & -1 \\
\hline 14. & Pemasangan Meter & 2 & 1 & -1 \\
\hline 15. & Pemel. Jaringan & 1 & 0 & -2 \\
\hline 16. & Pengaduan Rekening & 2 & 0 & -24 \\
\hline 17. & Pipa Dinas Bocor & 47 & 23 & -7 \\
\hline 18. & Pipa Distri Bocor & 116 & 109 & -161 \\
\hline 19. & Pipa Persil Bocor & 613 & 452 & -27 \\
\hline 20. & Stop Kran Bocor & 142 & 115 & -1.106 \\
\hline 21. & Total & 3.028 & 1.922 & \\
\hline & & & & -1 \\
\hline
\end{tabular}

Dengan adanya dua instansi yang menjalani tugas untuk menerima pengaduan pelanggan hal ini mengindikasikan bahwa tidak adanya titik kontak tunggal (Single Point of Contact) sebagai jalur utama satu pintu dalam hal penanganan masalah pelanggan, dikarenakan Bagian Humas dan Hublang secara teknis sama-sama menjalankan tugas untuk menerima pengaduan pelanggan. Hal ini berdampak pada timbulnya kesenjangan sistem kerja antara Bagian Humas dan Hublang karena ada perbedaan terhadap Prosedur Operasional Standar (Standard Operation Procedure) dalam menetapkan kategori dan identifikasi sebuah masalah sehingga membuat teknisi sulit 
untuk melihat prioritas masalah yang akan diselesaikan. Dan hambatan lain adalah dimana setiap laporan pengaduan yang masuk ke Bagian Humas dan Hublang tidak dapat diselesaikan pada hari itu juga, sehingga data laporan pengaduan yang masuk menjadi menumpuk [13].

Berdasarkan latar belakang diatas perlu dirancang suatu aplikasi Helpdesk berbasis web sebagai pusat pengaduan perihal pelayanan terhadap pelanggan agar dapat memperbaiki dan menyelesaikan permasalahan layanan. Aplikasi ini mampu mengirimkan keluhan ke unit yang bertanggung jawab sebagai dampak insiden terhadap layanan secepat mungkin sehingga keluhan atau masalah cepat ditangani [11].

\section{METODOLOGI PENELITIAN}

Dalam penulisan skripsi ini penulis menggunakan metode penelitian sebagai berikut:

1. Studi Kasus

Dalam hal ini data-data yang didapat oleh penulis diperoleh secara langsung karena penulis terlibat langsung dengan obyek penelitian yang dibahas yang terdiri dari:

a. Metode Observasi

Pada metode ini penulis melakukan tinjauan dan pengamatan langsung di perusahaan Kota Bekasi serta mengumpulkan data-data yang dibutuhkan.

b. Metode Wawancara

Dalam metode ini berkenaan langsung bertatap muka dengan pihakpihak terkait di internal Perusahaan kota Bekasi untuk menanyakan hal-hal yang berhubungan dengan penyusunan skripsi ini.

2. Penelitian Kepustakaan, dalam metode ini penulis mengambil data sebagai bahan acuan teori dari buku-buku yang ada di perpustakaan.

3. Metode konsep desain pengembangan perangkat lunak, menggunakan Metode Pengembangan Sistem Website Design Method. Model Website Design Method adalah model yang menyediakan bentuk permodelan dan metode sistematik untuk membangun aplikasi berbasis web. WSDM menjadikan target pengguna dan kebutuhannya yang berbeda-beda sebagai landasan dalam memulai proses desain, struktur utama aplikasi web kemudian diturunkan dari data pengguna target tersebut (1)

Website Design Method (WSDM) dikembangkan pada tahun 1998 oleh De Troyer dan Leune metode ini bertujuan untuk memisahkan focus perancangan dengan memberikan bentuk pemodelan dan metode sistematik untuk membangun aplikasi web. WSDM menjadikan target pengguna dan kebutuhannya yang berbeda-beda sebagai landasan dalam memulai proses desain, struktur utama aplikasi web kemudian diturunkan dari data pengguna tersebut [2]. 


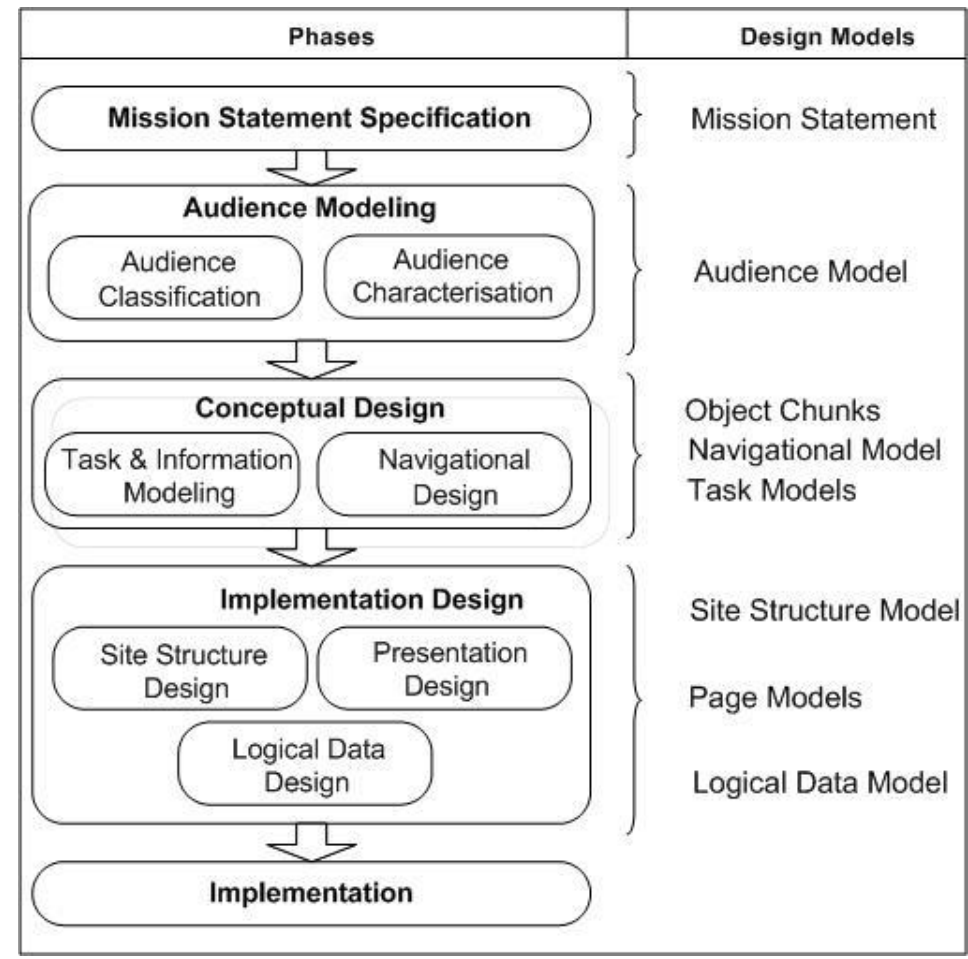

Gambar 2. Alur model rancangan sistem WSDM(3)

Dan setiap tahap desain berfokus pada satu aspek tertentu dari siklus desain web seperti Kebutuhan dan Analisis tugas, Data dan Fungsionalitas Pemodelan, Pemodelan Navigasi dan Presentasi Pemodelan dan Implementasi. WSDM memilki 5 tahap pengembangan yang berkelanjutan yaitu adalah:

\section{a) Pernyataan Misi (Mission Statement Spesification)}

Tahap pertama dalam WSDM adalah menentukan Misi Pernyataan dari aplikasi web yang akan dibangun. Tujuan aplikasi web harus didefinisikan terlebih dahulu, sehingga setelah perancangan dimulai akan mudah dalam menentukan menentukan keputusan yang akan diambil berkaitan dengan spesifikasi aplikasi web yang diinginkan.

Dalam Fase-fase perancangan selanjutnya, Pernyataan Misi bertindak sebagai dasar untuk menentukan informasi dan dan fungsi apa yang dibutuhkan, bagaimana bagaimana membuat strukturnya dan bagaimana menyampaikannnya.

\section{b) Pemodelan pengguna (Audience Modelling)}

Pada fase ini adalah mengidentifikasi pengguna dengan lebih spesifik karena $W S D M$ adalah metode yang berorientasi kepada pengguna maka definisi pengguna harus jelas. Definisi Target User yang disebutkan pada fase pertama kemudian diperbaiki lagi dalam Audience Class. Hal ini dilakukan dengan melalui dua sub fase, yaitu klasifikasi pengguna (Audience Classification) dan karakterisasi pengguna (Audience Characterization). 


\section{c) Rancangan konseptual (Conceptual Design)}

Tujuan dari Conseptual Design adalah untuk mengubah data-data tersebut menjadi data tingkat tinggi, dengan deskripsi formal. Fase rancangan konseptual berfokus pada pembahasan secara konsep tentang apa (What) dan bagaimana (How) komponen aplikasi diolah.

\section{d) Pelaksanaan rancangan (Implementation Design)}

Tujuan dari Implementation Design adalah sebagai pelengkap dari Rancangan Konseptual dengan menambahkan detil-detil yang diperlukan untuk implementasi.

\section{e) Pelaksanaan (Implementation)}

Fase terakhir adalah Implementation, pada fase ini semua informasi yang dihasilkan dari fase-fase sebelumnya diolah menjadi halaman-halaman web konkrit. Dari semua masukan tersebut kemudian aplikasi web dibangun menggunakan bahasa dan platform pengembangan yang dipilih. Dalam ITIL versi 3, Helpdesk adalah titik sentral di dalam integrasi domain ITIL dan salah satu fungsi kunci tahap di dalam domain Service Operation. Helpdesk dirancang untuk memenuhi kebutuhan komunikasi antara pengguna dan IT Support, seperti Incident Management, Problem Management dan Change Managemens [4].

Helpdesk bertujuan menampung insiden (incidents) dan permintaan layanan (request), kemudian meneruskan insiden dan permintaan layanan ke dalam proses TI, oleh karena itu Helpdesk perlu berintegrasi dengan baik dengan proses ITIL lain. Keuntungan dalam implementasi Helpdesk yang, antara lain sebagai berikut.

1. Peningkatan akses ke layanan melalui satu titik kontak pengguna.

2. Meningkatkan kualitas kepuasan pelanggan dan kualitas layanan yang lebih baik.

3. Meningkatkan kemampuan untuk komunkasi dan berbagi informasi dengan pengguna layanan.

4. Meningkatkan kemampuan untuk memberikan layanan kepada pengguna secara proaktif.

5. Efisiensi sumber daya TI dan aktivitas pengguna menjadi lebih terkontrol dan tata kelola TI menjadi lebih baik.

6. Pemecahan masalah menjadi lebih cepat.

7. Meningkatkan produktivitas baik untuk pengguna maupun untuk divisi TI.

8. Informasi yang dikumpulkan menjadi lebih berkualitas sehingga mendukung proses pengambilan keputusan.

Posisi Helpdesk dalam kerangka kerja ITIL bersama dengan fungsi dan proses lain ditunjukan pada gambar 3. pada gambar tersebut dijelaskan bahwa semua insiden (incident) dan permintaan untuk perubahan (Request for Change) harus melalui Helpdesk sebagai titik kontak dengan pengguna untuk diteruskan kepada proses dan fungsi lainnya dalam kerangka kerja 
ITIL versi 3 proses tersebut kaitannya dengan Helpdesk dapat dijelaskan sebagai berikut:

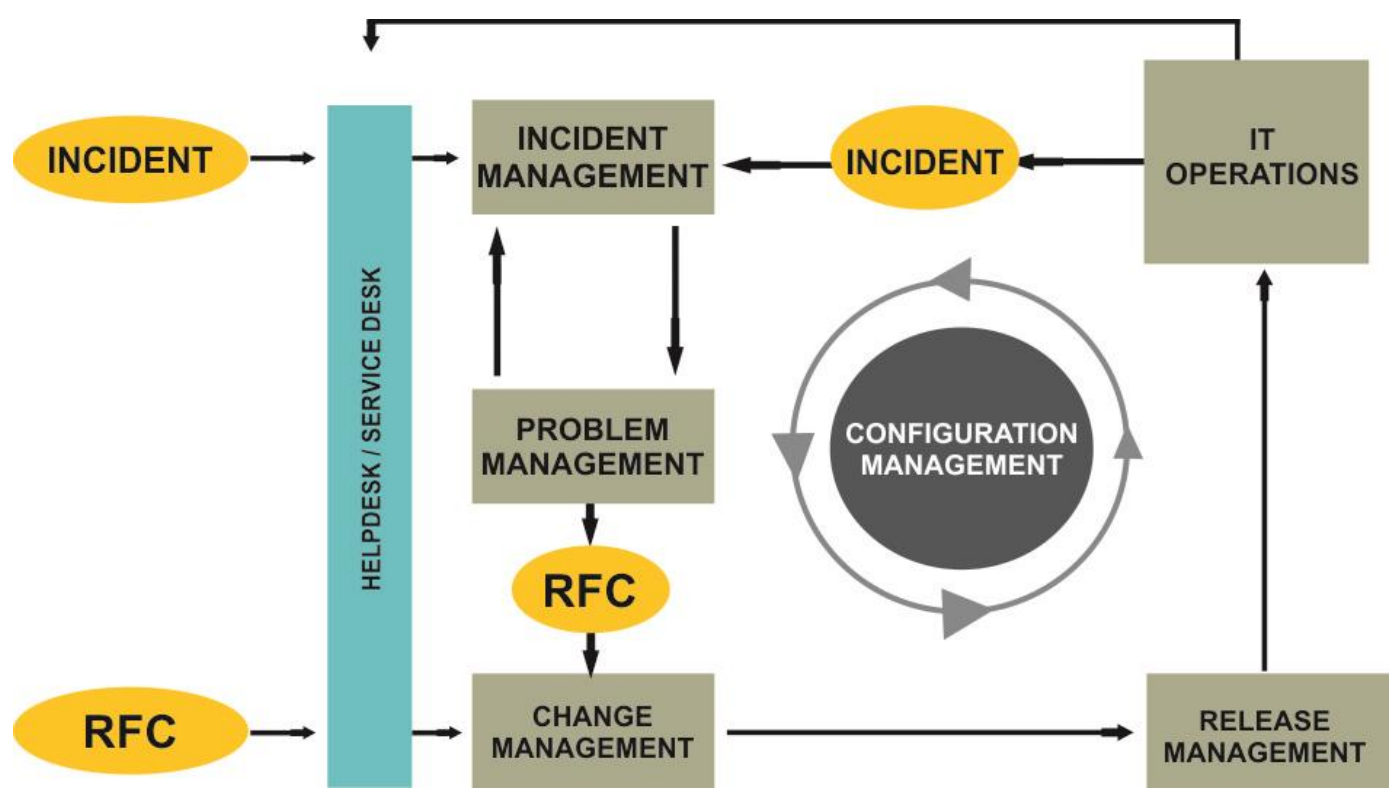

Gambar 3. Posisi Helpdesk diantara fungsi di dalam ITIL [5]

1. Change and Release Management.

Helpdesk bertindak sebagai titik pusat masukan dari Request for change (RFC), kemudian Helpdesk bisa mengkoordinasikan pemasangan atau perubahan instalasi pada sistem klien.

2. Configuration Management.

Ketika merekam sebuah Incidents, Helpdesk bisa mengakses Configuration Management Database (CMDB) untuk memverifikasi informasi dari sumber daya pengguna.

3. Service Level Management.

Helpdesk bisa memberikan layanan TI dengan standar dan ketentuan yang sudah ditetapkan, dan diikuti oleh semua pihak yang terlibat

\section{HASIL DAN PEMBAHASAN}

Sebelum sistem informasi di bangun di dalam konsep WSDM perlu di definisikan tahapan-tahapan yang dilalui pada saat perancangannya. Berikut adalah beberapa tahapan dalam proses perancangan Sistem informasi Helpdesk [15][16]:

1. Pernyataan Misi (Mission Statement)

Dalam fase ini adalah proses menentukan informasi dan fungsi yang dibutuhkan seperti struktur dan cara penyampaiannya dalam bentuk sebuah pernyataan. Berikut adalah bentuk pernyataannya:

a. Tujuan (Purpose)

Membangun sebuah aplikasi sistem informasi Helpdesk berbasis web sebagai titik kontak tunggal untuk staf Hubungan Langganan dan 
Hubungan Masyarakat dalam penanganan pengaduan pelanggan agar lebih efektif dan efisien untuk mengelola laporan pengaduan tersebut dan juga sebagai fasilitas staf untuk bertukar informasi.

b. Topik Bahasan (Subject)

Sistem Informasi Helpdesk perusahaan distribusi air bersih Kota Bekasi

c. Pengguna yang dituju (Target User)

Staf Bagian Perencanaan Teknik, Staf Bagian Hubungan Langganan, Staf Bagian Produksi dan Staf Bagian Humas.

2. Pemodelan Pengguna (Audience Modelling)

Pada tahap ini adalah mendefinisikan pengguna target user untuk sistem. Hal ini telah disebutkan dalam fase pernyataan misi tetapi akan dikaji ulang kedalam dua sub fase, yaitu klasifikasi pengguna (Audience Clasification) dan karakterisasi pengguna (Audience Characterization)

a. Klasifikasi Pengguna (Audience Clasification)

Tipe pengguna diidentifikasikan secara detil dan diklasifikasikan ke dalam Audience Class. Tipe pengguna sistem informasi ini antara lain staf Hubungan langganan dan Humas yang bertujuan untuk menampung dan mengidentifikasi pengaduan pelanggan, Pengguna level Teknisi yang bertugas untuk menyelesaikan permasalahan pelanggan yang di kirim lewat aplikasi Helpdesk, kepala bagian teknisi yang bertugas untuk memonitoring aplikasi Helpdesk, Pengguna Kepala Bagian Teknisi, Teknisi merupakan Audience Subclass dari Audience Class adalah staf Hublang dan Humas.

b. Karakterisasi Pengguna (Audience Characterization)

Karakteristik ini merupakan atribut umum bagi pengguna yang berpengaruh terhadap interaksinya dengan aplikasi. Dalam sub fase ini, karakteristik tambahan didefinisikan untuk tiap Audience Class, Contoh karakteristik ini antara lain keterampilan dalam mengoperasikan komputer, pengalaman menggunakan alat teknologi informasi dan pengetahuan tentang maksud dan tujuan sistem informasi.

3. Rancangan Konseptual (Conceptual Design)

Pada fase sebelumnya, Audience Class calon pengguna dan karateristiknya telah didefinisikan. Tujuan dari rancangan konseptual adalah untuk mengubah data-data tersebut menjadi data tingkat tinggi (high-level), dengan deskripsi formal. Fase rancangan konseptual berfokus pada pembahasan secara konsep tentang apa dan bagaimana komponen aplikasi ini diolah. Masing-masing objek model tersebut disusun menjadi sebuah struktur tunggal yang menjadi struktur konsep aplikasi Helpdesk seperti gambar berikut. 
Jurnal Sains Komputer \& Informatika (J-SAKTI)

Volume 3 Nomor 2 September 2019, pp. 201-211

ISSN:2548-9771/EISSN:2549-7200

http://tunasbangsa.ac.id/ejurnal/index.php/jsakti

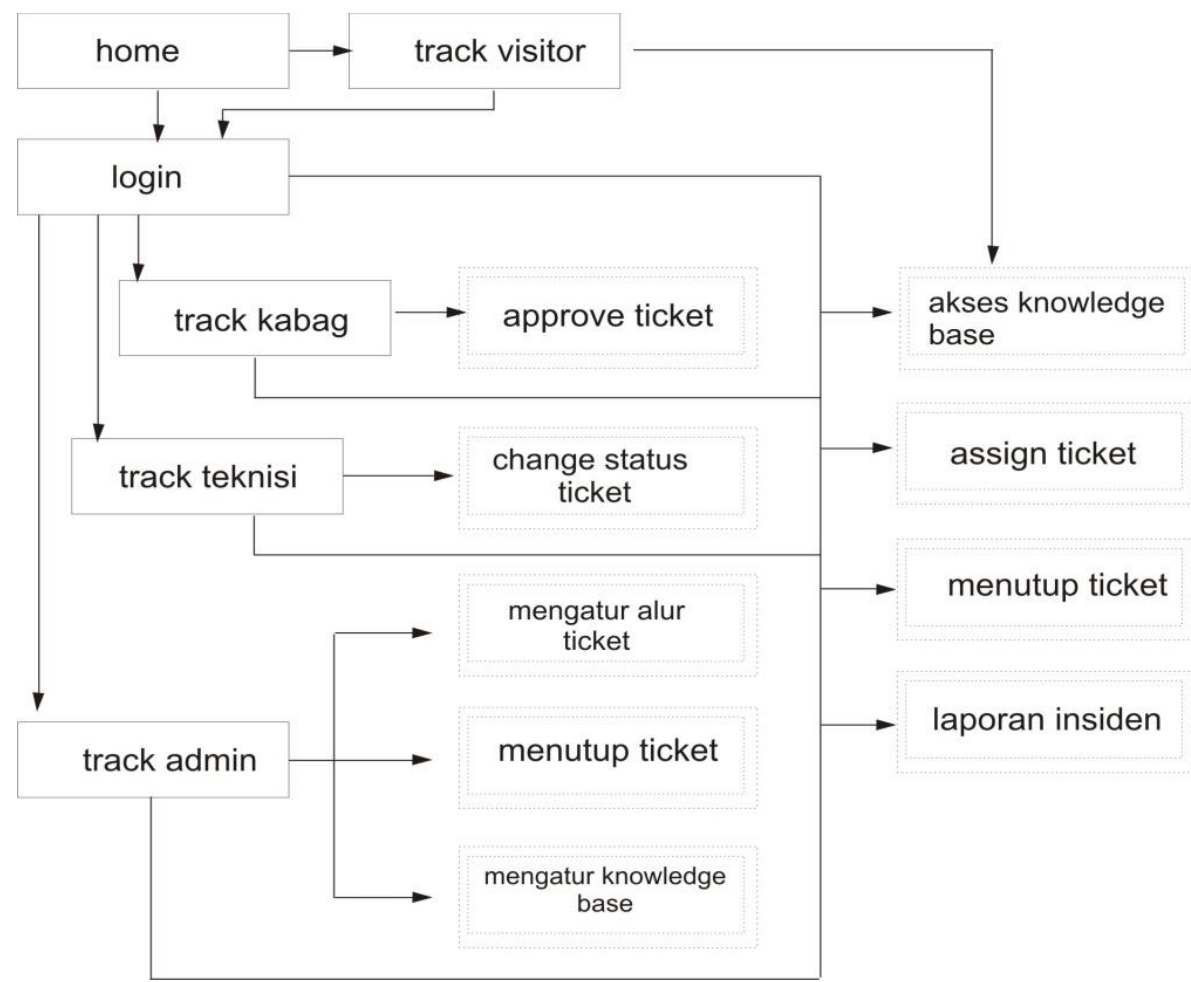

Gambar 4. Rancangan konseptual struktur aplikasi Helpdesk

4. Rancangan Implementasi (Implementation Design)

Tujuan dari Rancangan Implementasi adalah sebagai pelengkap rancangan konseptual dengan menambahkan detil-detil yang diperlukan untuk implementasi.

5. Implementasi (Implementation)

Fase terakhir adalah Implementasi. Pada fase ini semua informasi yang dihasilkan dari fase-fase sebelumnya diolah menjadi halaman web. Fase implementasi mengambil masukan berupa objek model beserta informasinya. Berikut gambar skema implementasi perancangannya:

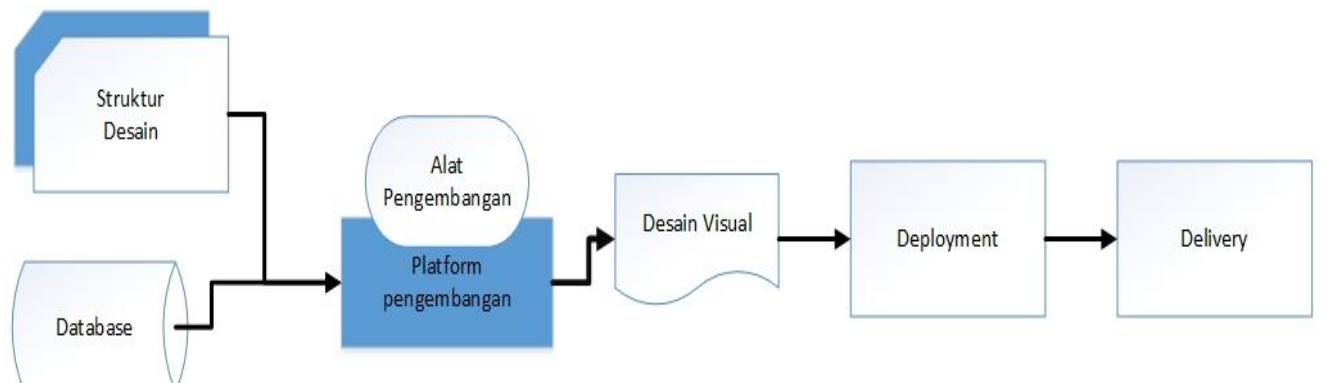

Gambar 5. Skema implementasi perancangan aplikasi Helpdesk [15] 


\subsection{Tampilan Aplikasi Helpdesk}

Berkut tampilan halaman utama seperti ditunjukkan pada gambar berikut:

\section{(9)} Sgnnas Administratores:

마일 모 New Ticket
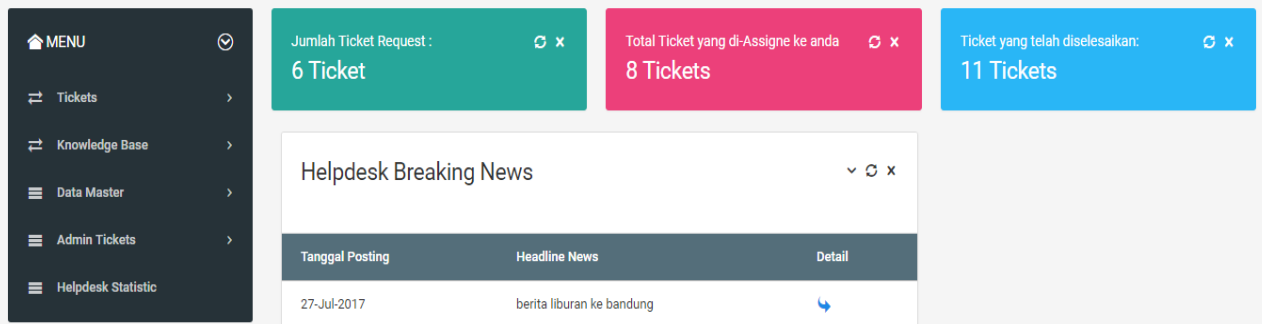

Helpdesk Breaking News
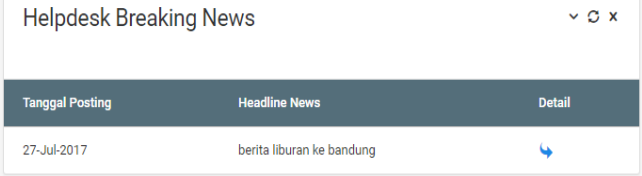

Gambar 6. Tampilan Halaman Utama

Pembangunan aplikasi dibuat menggunakan Php dan basis data MySql [6][10]. Merupakan tampilan utama aplikasi Helpdesk untuk admin, tampilan tersebut digunakan admin untuk mengelola data pengguna dan ticket di aplikasi Helpdesk.

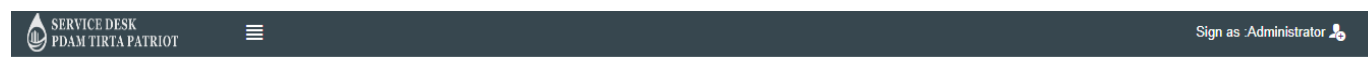

$\square$ Home $\quad$ N New Ticket
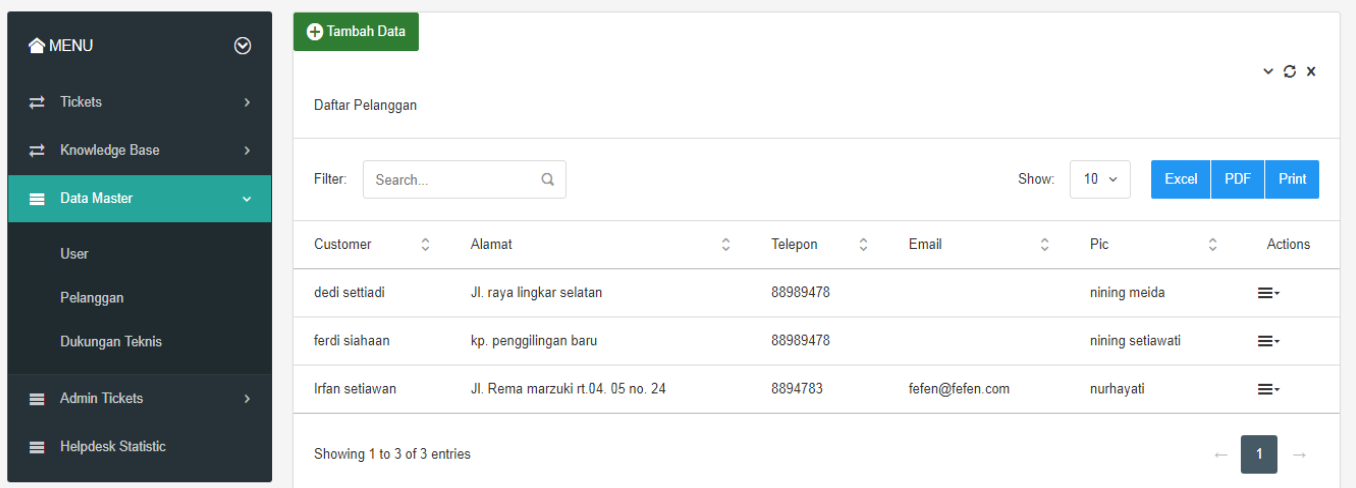

Gambar 7. Tampilan Halaman daftar data pelanggan

menampilkan informasi pelanggan yang akan di dukung dalam aplikasi Helpdesk. Disini admin dapat menambah data pelanggan baru, mengedit dan menghapus. 


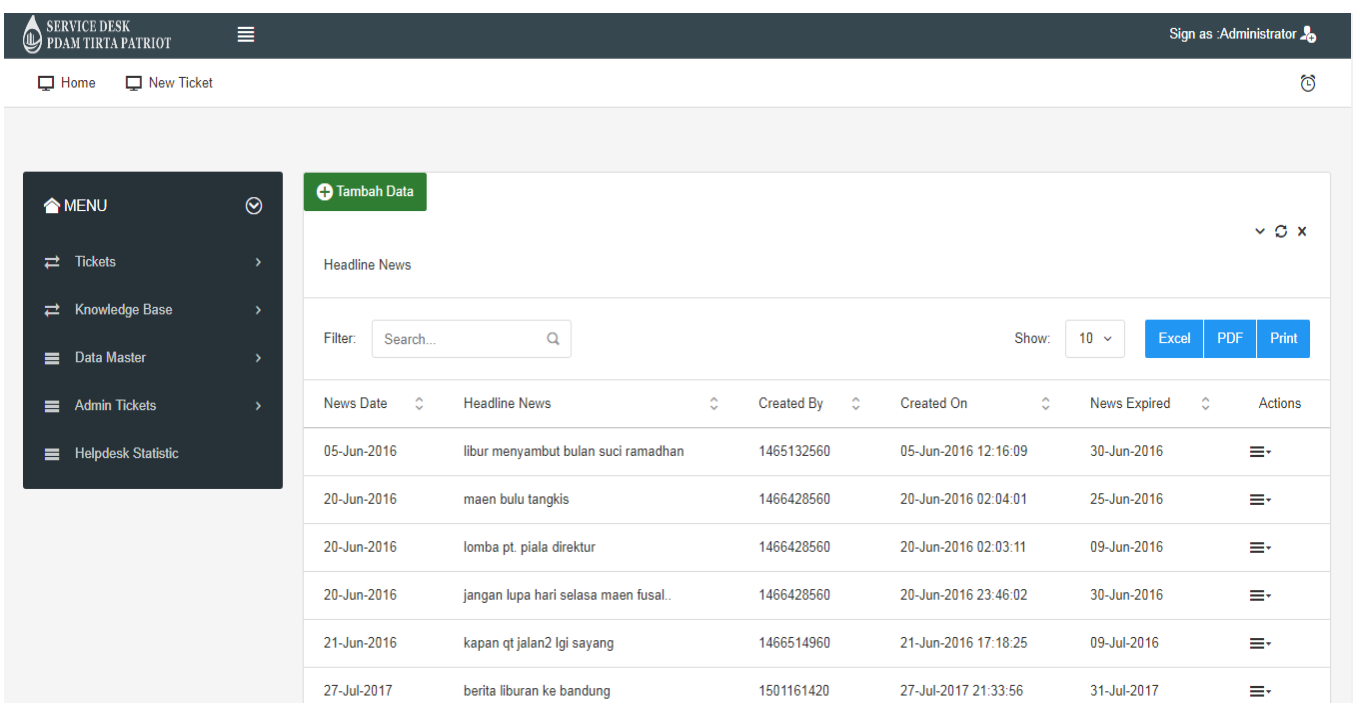

Gambar 8. Tampilan Halaman berita Helpdesk

Halaman berita Helpdesk adalah halaman yang berisi informasi umum tentang seputar lingkungan perusahaan. Tujuannya agar semua pengguna, terutama teknisi mengetahui berita tersebut.

\section{SIMPULAN}

Berdasarkan penelitian yang sudah dilakukan mengenai perancangan aplikasi Helpdesk dengan metode Website design method dalam rangka penerapan manajemen insiden pada domain ITIL Service Operation, maka dapat di ambil kesimpulan sebagai berikut.

a. Dengan adanya sistem Helpdesk berbasis web yang digunakan untuk menampung data keluhan dan permasalahan pelanggan diharapkan bisa langsung dikirimkan ke unit yang bertanggung jawab sehingga bisa mengurangi prosedur yang terlalu panjang dan keluhan pelanggan bisa langsung cepat ditangani.

b. Hasil keluaran ataupun informasi yang dihasilkan oleh sistem ini berbentuk grafik yang menyajikan jumlah SLA yang sering dilanggar, jumlah ticket yang ditutup dan ticket yang telah dimasukan kedalam sistem.

c. Dengan dirancangnya aplikasi Helpdesk ini bisa menjadi sebuah aplikasi yang digunakan untuk pusat permintaan layanan oleh staf.

d. Perancangan sistem Helpdesk berbasis web untuk menampung keluhan dan permasalahan pelanggan.

\section{DAFTAR PUSTAKA}

[1] Anon. 2012. "Implementasi ITIL® V3 Framework Pada Perancangan Aplikasi Service Desk Management Berorientasi User3." JNTETI (Jurnal Nasional Teknik Elektro Dan Teknologi Informasi) 1(2):10-20.

[2] Kröll, Mark. 2009. "WSDM 2009 Conference Review." ACM SIGWEB Newsletter (Spring):1-6. 
[3] Magdalena, Lena and Kata Kunci. 2011. "Analisis Problem Management Pada IT Helpdesk Dengan Implementasi ITSM Dan SLA (Studi Kasus : Citigroup Indonesia)." Jurnal Digit.

[4] Sipayung, Evasaria M., Cut Fiarni, and Ernest Aditya. 2017. "Perancangan Sistem Informasi Helpdesk Menggunakan Framework ITIL V3." Jurnal Nasional Teknik Elektro Dan Teknologi Informasi (JNTETI).

[5] Troyer, Olga De, Sven Casteleyn, and Peter Plessers. 2008. "WSDM: Web Semantics Design Method."

[6] Basuki, A. P. (2014). Proyek Membangun Website Berbasis PHP dengan Codeigniter. Yogyakarta: Lokomedia.

[7] Britain, G. (2007). Office of Government Commerce Service Operation (Vol. 4). The Stationery Office.

[8] Cahyaningtyas, A., Rahardja, Y., \& Fritz, A. (2012). Audit Sistem Informasi dengan ITIL Version 3 Sub Domain Service Desk, Incident Management dan Problem Management di Bidang Keuangan dishubkombudpar Kota Salatiga. Jurnal Teknologi Informasi-Aiti , 175176.

[9] Kadir, A. (2014). Pengenalan Sistem Informasi Edisi Revisi. Yogyakarta: ANDI.

[10] Kasiman, P. (2006). Aplikasi WEB dengan PHP dan MySQL. Yogyakarta: ANDI.

[12] Maita, I., \& Sapri, A. (2016). Analisa Tata Kelola Teknologi Informasi dengan Best Practice ITIL. Jurnal Rekayasa dan Manajemen Sistem Informasi .

[13] Office of Government Commerce. (2011). The IT Infrastructure Library An Introductory Overview of ITIL $\AA$ V3. London: The Stationery Office.

[14] Putri, E. S. (2015). Peran Public Relations dalam meningkatkan kepuasan pelanggan di PDAM Tirta Patriot Kota Bekasi.

[15] Santoso, H. (2014). Helpdesk System berbasis OOP dan PDO dengan PHP. Yogyakarta: Lokomedia.

[16] Yulianingsih. (2011). Rancangan Tata kelola Servicedesk berbasis Information Technology Infrastruktur Library. Jurnal Ilmiah Faktor Exacta 